\title{
Anaplastic lymphoma kinase-positive anaplastic large-cell lymphoma with involvement of the urinary bladder: a case report and review of literature
}

\author{
Xiaoqin Liang ${ }^{1,2}$ \\ Yingmei Wang' \\ Jinsong Zhang ${ }^{3}$ \\ Hong Cheng' \\ Jinsui Wang ${ }^{2}$ \\ Yamei Dang ${ }^{2}$ \\ Haomin $\mathrm{Li}^{1,4}$ \\ Ru Zhou' \\ Jing Zhang' \\ Qing Qiao ${ }^{5}$
}

'State Key Laboratory of Tumor Biology, Department of Pathology, Xijing Hospital, The Fourth Military Medical University, Xi'an, Shaanxi, People's Republic of China;

${ }^{2}$ Department of Pathology, Gansu Provincial People's Hospital, Lanzhou, Gansu, People's Republic of China; ${ }^{3}$ Department of Radiology, Xijing Hospital, The Fourth Military Medical University, Xi'an, Shaanxi, People's Republic of China; ${ }^{4}$ Department of Neurosurgery, First affiliated Hospital, China Medical University, Shenyang, Liaoning, People's Republic of China; ${ }^{5}$ Department of General Surgery, Tangdu Hospital, The Fourth Military Medical University, Xi'an, Shaanxi, People's Republic of China
This article was published in the following Dove Press journal:

OncoTargets and Therapy

19 May 2015

Number of times this article has been viewed
Abstract: We report a unique case of anaplastic large-cell lymphoma (ALCL) involving the urinary bladder in a 22-year-old man. The patient presented with left lower back pain for 4 weeks. The computed tomography (CT) scan demonstrated an exophytic nodule on the left bladder wall and abdominopelvic lymphadenopathy. Histologically, a population of large pleomorphic cells extensively infiltrated the lamina propria of the bladder. These cells were diffusely and strongly immunoreactive for CD30, ALK, EMA, and vimentin, but were negative for AE1/AE3, CK20, CK7, CK5/6, P63, SMA, HMB-45, pan-Melan, S-100, Myo D1, synaptophysin, CD56, desmin, CD15, CD20, Pax-5, and CD3. Few cells exhibited positive immunohistochemical staining of CD45. The patient underwent cyclophosphamide, doxorubicin, vincristine, and prednisone (CHOP) regime of chemotherapy and achieved a complete remission after four cycles. This case is the tenth documented case of systemic ALCL involving urinary bladder. Due to its rarity, it is important to be aware of the features of ALCL in bladder, and make prompt and accurate diagnosis.

Keywords: anaplastic large-cell lymphoma, anaplastic lymphoma kinase, urinary bladder

\section{Introduction}

Anaplastic large-cell lymphoma (ALCL) is a malignant lymphoma of T-cells, with constitutive expression of the high level of CD30 antigen. ${ }^{1}$ Its most frequent genetic alteration is a $(2 ; 5)(\mathrm{p} 23 ; \mathrm{q} 35)$ chromosomal translocation, which leads to the formation of nucleophosmin (NPM)-anaplastic lymphoma kinase (ALK) fusion protein, resulting in the upregulation of ALK protein. ${ }^{2,3}$ According to the current World Health Organization (WHO) classification, this tumor is further subdivided into two distinct subgroups: ALK-positive ALCL and ALK-negative ALCL. The ALK-positive ALCL is a clinically aggressive lymphoma that usually occurs in children and young adults. It is associated with an improved response to chemotherapy and a good prognosis. On the other hand, the ALK-negative ALCL occurs mainly in elderly individuals, and has a poor clinical course. ${ }^{4-7}$

Involvement of the urinary bladder by malignant lymphoma is infrequent. The most common types are mucosa-associated lymphoid tissue (MALT) lymphoma and diffuse large B-cell lymphoma (DLBCL). ALCL involving the urinary bladder is extremely rare. To the best of our knowledge, only nine cases have been documented to date. ${ }^{8-16}$ Herein, we report another case of a 22-year-old man with ALK-positive ALCL involving the urinary bladder, and specifically highlight its differential diagnosis and therapeutic methods.

\section{Case report}

A 22-year-old man presented with progressive left lower back pain for 4 weeks. A computed tomography (CT) scan showed an exophytic mass in the urinary bladder
Department of General Surgery, Tangdu Hospital, The Fourth Military Medical University, No I Xinsi Road,

Xi'an, Shaanxi 710038,

People's Republic of China

Tel +86298477773 I

Fax +862984773624

Email qqing44@fmmu.edu.cn
OncoTargets and Therapy 2015:8 II43-II47 (c) (1) (5) 2015 Liang et al. This work is published by Dove Medical Press Limited, and licensed under Creative Commons Attribution - Non Commercial (unported, v3.0) License. The full terms of the License are available at http://creativecommons.org/licenses/by-n/3.0/. Non-commercial uses of the work are permitted without any further permission how to request permission may be found at. http://www.dovepress.com/permissions.php 
(Figure 1A), as well as a left kidney hydronephrosis and abdominopelvic lymphadenopathy. The patient underwent cystoscopy, which revealed an exophytic broad-based mass measuring $4.5 \mathrm{~cm} \times 3.6 \mathrm{~cm}$ on the left wall of the urinary bladder (Figure 1B). Subsequent tissue biopsies were performed.

The bladder biopsies were fixed in buffered formalin and embedded in paraffin. A five-micrometer-thick section was stained with hematoxylin-eosin (H\&E) for routine microscopy. Immunohistochemical (IHC) staining was performed using the EnVision ${ }^{+}$Detection System (DAKO, Galway, Ireland). The IHC studies included AE1/AE3, CK20, EMA, vimentin, CK7, CK5/6, and P63 for carcinoma, synaptophysin and CD56 for neuroendocrine tumor, HMB-45, panMelan, and S-100 for melanoma, Myo D1, desmin, and SMA for rhabdomyosarcoma or inflammatory myofibroblastic tumors, and CD30, ALK, CD45, CD15, CD20, Pax-5, and CD3 for lymphohematopoietic malignancies.

Histologically, the lamina propria of the bladder was diffusely infiltrated by pleomorphic large cells (Figure 2A). The majority of tumor cells had pleomorphic nuclei, prominent nucleoli, and brisk mitotic activity (Figure 2B). There were small mature-appearing lymphocytes and eosinophils in the background. The urothelial mucosa was intact without the evidence of carcinoma in situ. IHC staining showed that tumor cells were diffusely and strongly positive for CD30 (Figure 2C), ALK (Figure 2D), EMA, and vimentin. They were negative with AE1/AE3 (Figure 2E), CK20, CK7, CK5/6, P63, SMA, HMB-45, pan-Melan, S-100, Myo D1, synaptophysin (Figure 2F), CD56, desmin, CD15, CD20,
Pax-5, and CD3. Few cells exhibited positive IHC staining of CD45. These results rendered a diagnosis of ALK-positive ALCL.

After pathological diagnosis was established, the patient underwent the cyclophosphamide, doxorubicin, vincristine, and prednisone (CHOP) regime of chemotherapy. He had responded well to the treatment. After four courses, a second CT scan revealed that both bladder mass and the lymphadenopathies had disappeared. The patient achieved a complete clinical and radiologic remission. The patient was alive and well 8 months after diagnosis.

\section{Discussion}

ALCL is an uncommon lymphoma. More than $40 \%$ of cases present with advanced disease (stage III and IV), and peripheral and abdominal lymphadenopathy, or extranodal and bone marrow involvement. ${ }^{13}$ In the present case, the neoplasm represented a systemic involvement although it was first detected in the bladder.

Systemic ALCL rarely involves the urinary bladder, especially with injury of the urinary system as the main clinical manifestation. A total of ten cases of ALCL involving the bladder, including the current case, have been documented..$^{8-16}$ In general, the mean age of the patients was 40 years (range, 22-78 years). Among them, six patients were less than 45 years old. Eight of the ten cases $(80 \%)$ of ALCL showed ALK-positive expression in the bladder. The cases showed a male predominance. All of them except one occurred in male patients. The most common presenting symptoms were upper tract obstruction and hematuria.
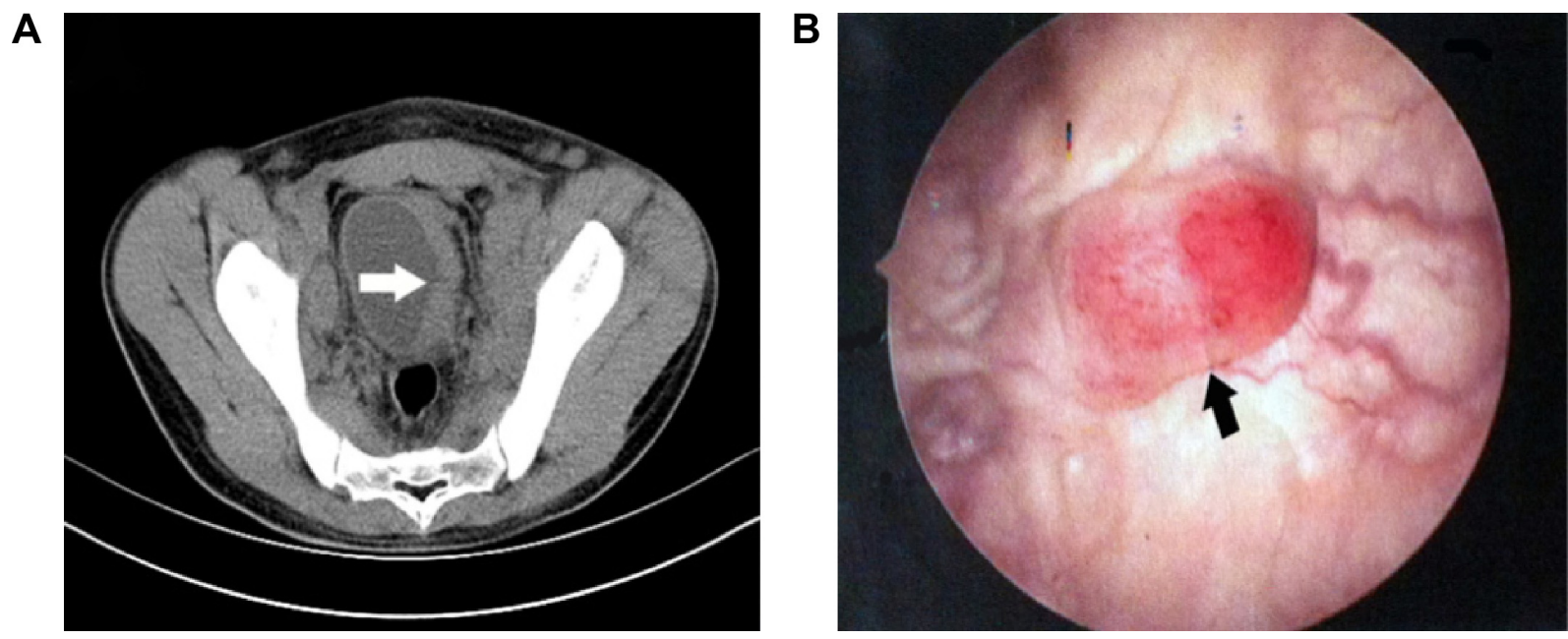

Figure I The images of CT and cystoscopy in a patient with ALK-positive ALCL involving the urinary bladder.

Notes: (A) Enhanced CT scan showing an exophytic broad-based nodular lesion (white arrow) on the left bladder wall; (B) Cystoscopy revealing an irregularly shaped nodule with congestive and hemorrhagic appearance (black arrow).

Abbreviations: CT, computed tomography; ALK, anaplastic lymphoma kinase; ALCL, anaplastic large-cell lymphoma. 

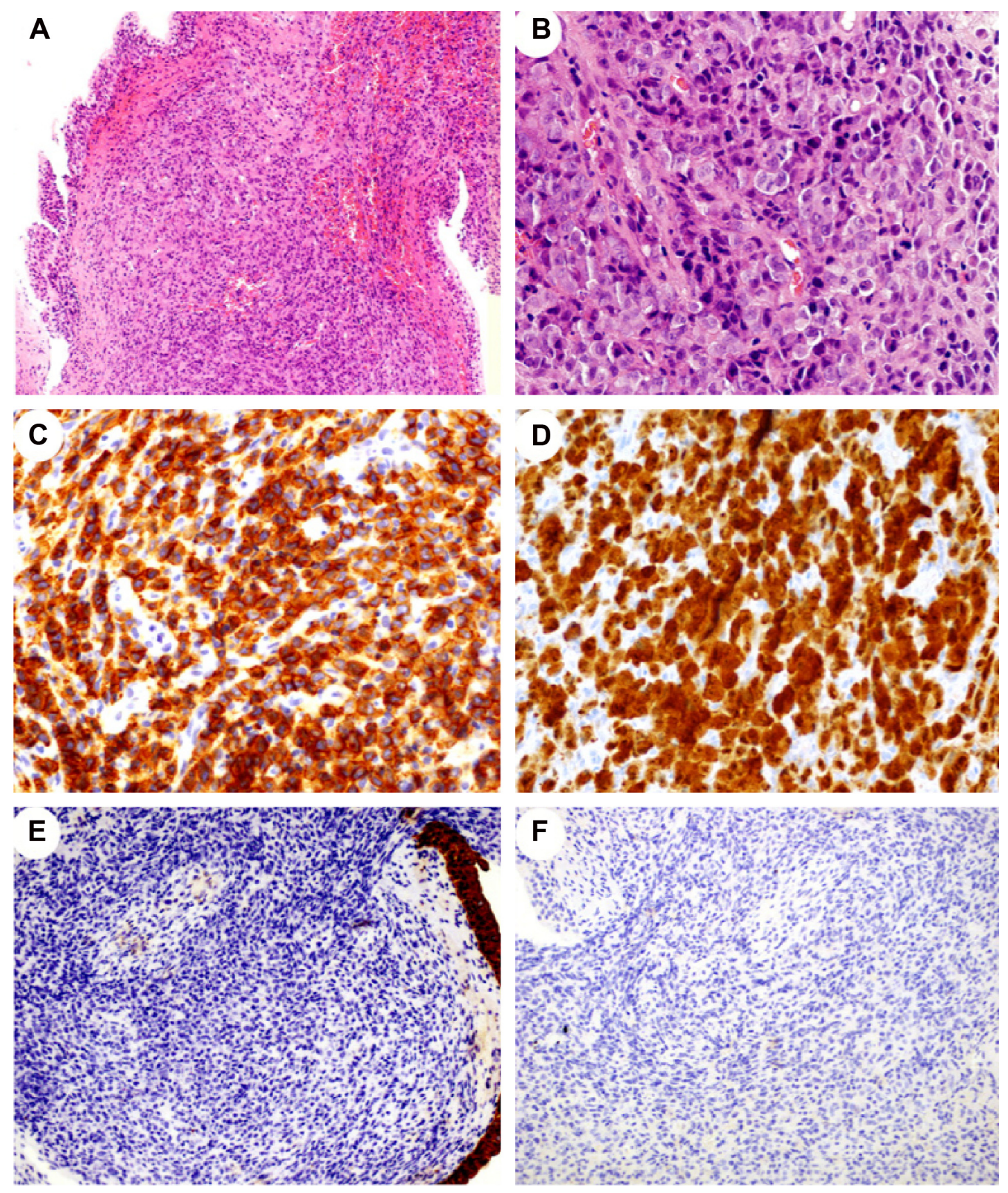

Figure $2 \mathrm{H \& E}$ and IHC staining in the urinary bladder sample of ALK-positive ALCL.

Notes: (A) Diffuse infiltration of tumor cells in the lamina propria of bladder (200x, H\&E); (B) Tumor cells with pleomorphic nuclei, prominent nucleoli, and brisk mitotic activity (400x, H\&E); (C) Strong immunoreactivity of CD30 with membrane staining pattern in neoplastic cells (400x, IHC); (D) A diffuse cytoplasmic and nuclear staining for ALK protein (400x, IHC); (E) Negative expression of AEI/AE3 in tumor cells (200x, IHC); (F) Tumor cells exhibiting negative expression for synaptophysin (200x, IHC).

Abbreviations: H\&E, hematoxylin-eosin; IHC, immunohistochemical; ALK, anaplastic lymphoma kinase; ALCL, anaplastic large-cell lymphoma.

Moreover, eight of ten patients underwent chemotherapy. The majority of them (six cases) were treated using the CHOP regime. Five of eight patients with follow-up data were alive and well. The mean survival time of patients after chemotherapy was 24.5 months. They had impressive response to multiagent chemotherapy and remained in clinical and/or radiologic remission.
Due to its rarity, it is important to be aware of the possibility of ALCL involving the urinary bladder. Morphologically, the distinctive feature is a population of pleomorphic, highly atypical cells with amphophilic or pale cytoplasm diffusively and extensively infiltrating in the lamina propria and/or the muscular layer of the urinary bladder. The nuclei of tumor cells are round, oval, or lobulated with 
coarse granular chromatin, and have prominent nucleoli. The differential diagnosis for this malignant process is broad, including embryonal rhabdomyosarcoma, poorly differentiated or sarcomatoid carcinoma, neuroendocrine tumor, other lymphomas (such as DLBCL and Hodgkin lymphoma), metastatic amelanotic melanoma, and even inflammatory myofibroblastic tumors. ${ }^{15}$ Therefore, it is necessary to use IHC staining to distinguish ALCL from aforementioned tumors. Embryonal rhabdomyosarcoma and inflammatory myofibroblastic tumor may express ALK, but are negative for CD30 and EMA. They also express markers of myxoid/myofibroblastic differentiation, such as smooth muscle actin (SMA) and desmin. The melanoma cells are often positive for HMB-45, pan-Melan, and S-100 protein, whereas ALCL cells are negative for these markers. The tumor cells in ALCL are sometimes strongly positive for EMA. Rare cases with expression of keratin have been described in ALCL. ${ }^{17}$ However, ALCL is readily distinguishable from carcinoma. Unlike ALCL, the neuroendocrine tumor cells are positive for CD56 and synaptophysin. Moreover, the diagnosis of DLBCL and Hodgkin lymphoma can be excluded if the tumor cells are diffusely positive for CD30 and ALK, and negative for B-cell markers (CD20, Pax-5, etc) or CD15.

In general, surgery, chemotherapy, radiotherapy, and combinations of the above-mentioned treatments are the recommended therapies for ALCL. ${ }^{18}$ The patients' characteristics, such as age, disease stage, and the association with systemic disease, should be considered. Generally, systemic chemotherapy is the preferred treatment, and an aggressive surgical procedure should be avoided. The combination of cyclophosphamide, doxorubicin, vincristine, and prednisone (CHOP) is the most common regimen. It has been reported that about $90 \%$ cases of ALK-positive ALCL patients have responded to the $\mathrm{CHOP}$ regimen, and have a remarkably better prognosis than those patients with ALK-negative ALCL. ${ }^{19,20}$ In the present case, the patient underwent CHOP chemotherapy, and achieved a complete remission after four cycles of chemotherapy.

\section{Conclusion}

In conclusion, we describe an extremely rare case of ALKpositive ALCL presenting with symptomatic bladder involvement. This tumor is characterized by a pleomorphic large cell with strong expression of CD30 and ALK. It is important to be aware of the morphological features and differential diagnosis, and making accurate diagnosis is crucial for therapeutic regimen selection.

\section{Acknowledgment}

This work was supported by National Natural Science Foundations of China (NSFC 81070582 and 81372783) and Technological and Social Development Research Project of Shaanxi Province (2014K11-03-03-03).

\section{Disclosure}

The authors report no conflicts of interest in this work.

\section{References}

1. Falini B, Pileri S, Pizzolo G. CD30 (Ki-1) molecule: a new cytokine receptor of the tumor necrosis factor receptor superfamily as a tool for diagnosis and immunotherapy. Blood. 1995;85(1):1-14.

2. Fischer P, Nacheva E, Mason DY, et al. A Ki-1 (CD30)-positive human cell line (Karpas 299) established from a high-grade non-Hodgkin's lymphoma, showing a 2;5 translocation and rearrangement of the T-cell receptor beta-chain gene. Blood. 1988;72(1):234-240.

3. Kuefer MU, Look AT, Pulford K, et al. Retrovirus-mediated gene transfer of NPM-ALK causes lymphoid malignancy in mice. Blood. 1997;90(8):2901-2910.

4. Piccaluga PP, Gazzola A, Mannu C, et al. Pathobiology of anaplastic large cell lymphoma. Adv Hematol. 2010;2010:345053. doi: $10.1155 / 2010 / 345053$.

5. Kinney MC, Higgins RA, Medina EA. Anaplastic large cell lymphoma: twenty-five years of discovery. Arch Pathol Lab Med. 2011; 135(1):19-43.

6. Falini B, Bigerna B, Fizzotti M, et al. ALK expression defines a distinct group of T/null lymphomas ("ALK lymphomas") with a wide morphological spectrum. Am J Pathol. 1998;153(3):875-886.

7. Stein H, Foss HD, Dürkop H, et al. CD30(+) anaplastic large cell lymphoma: a review of its histopathologic, genetic, and clinical features. Blood. 2000;96(12):3681-3695.

8. Allory Y, Merabet Z, Copie-Bergman C, Lange F, Yiou R, Gaulard P. Sarcomatoid variant of anaplastic large cell lymphoma mimics ALK1-positive inflammatory myofibroblastic tumor in bladder. Am J Surg Pathol. 2005;29(6):838-839.

9. Blick C, Abdelhadi S, Bailey D, Muneer A. Anaplastic, T-cell, non-Hodgkin's lymphoma presenting with haematuria. Scientific World Journal. 2008;8:342-345.

10. Pai SA, Naresh KN, Patil PU. Systemic anaplastic large cell lymphoma presenting as a bladder neoplasm. Leuk Lymphoma. 2004;45(4): 841-843.

11. Hughes M, Morrison A, Jackson R. Primary bladder lymphoma: management and outcome of 12 patients with a review of the literature. Leuk Lymphoma. 2005;46(6):873-877.

12. Murphy AJ, O'Neill P, O'Brien F, et al. Anaplastic large cell lymphoma: a unique presentation with urinary bladder involvement: a case report. Int J Surg Pathol. 2005;13(4):369-373.

13. Gomez-Roman JJ, Cobo ML, Val-Bernal JF. Anaplastic lymphoma kinase-positive anaplastic large cell lymphoma presenting as a bladder neoplasm. Pathol Int. 2008;58(4):249-252.

14. Proca DM, De Renne L, Marsh WL Jr, Keyhani-Rofagha S. Anaplastic large cell lymphoma in a human immunodeficiency virus-positive patient with cytologic findings in bladder wash: a case report. Acta Cytol. 2008;52(1):83-86.

15. Chen H, Li Y, Nand S, Quek ML, Kini AR, Barkan GA. Anaplastic large cell lymphoma involving the urinary bladder: A case report and review of the literature. Diagn Cytopathol. 2015;43(1): $60-65$.

16. Kobayashi M, Asano N, Fukushima M, Honda T. Three different histological subtypes of Epstein-Barr virus-negative post-transplant lymphoproliferative disorder in a patient with hepatitis $\mathrm{C}$ infection. Int J Hematol. 2014;100(3):307-311. 
17. Gustmann C, Altmannsberger M, Osborn M, Griesser H, Feller AC. Cytokeratin expression and vimentin content in large cell anaplastic lymphomas and other non-Hodgkin's lymphomas. Am J Pathol. 1991; 138(6):1413-1422.

18. Horasanli K, Kadihasanoglu M, Aksakal OT, Ozagari A, Miroglu C. A case of primary lymphoma of the bladder managed with multimodal therapy. Nat Clin Pract Urol. 2008;5(3):167-170.

19. Savage KJ, Harris NL, Vose JM, et al; International Peripheral T-Cell Lymphoma Project. ALK- anaplastic large-cell lymphoma is clinically and immunophenotypically different from both ALK+ ALCL and peripheral T-cell lymphoma, not otherwise specified: report from the International Peripheral T-Cell Lymphoma Project. Blood. 2008;111(12):5496-5504.
20. Lowe EJ, Sposto R, Perkins SL, et al; Children's Cancer Group Study 5941. Intensive chemotherapy for systemic anaplastic large cell lymphoma in children and adolescents: final results of Children's Cancer Group Study 5941. Pediatr Blood Cancer. 2009;52(3):335-339.

\section{Publish your work in this journal}

OncoTargets and Therapy is an international, peer-reviewed, open access journal focusing on the pathological basis of all cancers, potential targets for therapy and treatment protocols employed to improve the management of cancer patients. The journal also focuses on the impact of management programs and new therapeutic agents and protocols on

\section{Dovepress}

patient perspectives such as quality of life, adherence and satisfaction. The manuscript management system is completely online and includes a very quick and fair peer-review system, which is all easy to use. Visit http://www.dovepress.com/testimonials.php to read real quotes from published authors.

Submit your manuscript here: http://www.dovepress.com/oncotargets-and-therapy-journal 